\title{
Inequalities in access to healthcare by local policy model among newly arrived refugees: evidence from population-based studies in two German states
}

\author{
Judith Wenner ${ }^{1}$, Louise Biddle ${ }^{2}$, Nora Gottlieb ${ }^{1,3}$ and Kayvan Bozorgmehr ${ }^{1,2^{*}}$ (D)
}

\begin{abstract}
Background: Access to healthcare is restricted for newly arriving asylum seekers and refugees (ASR) in many receiving countries, which may lead to inequalities in health. In Germany, regular access and full entitlement to healthcare (equivalent to statutory health insurance, $\mathrm{SHI}$ ) is only granted after a waiting time of 18 months. During this time of restricted entitlements, local authorities implement different access models to regulate asylum seekers' access to healthcare: the electronic health card (EHC) or the healthcare voucher (HV). This paper examines inequalities in access to healthcare by comparing healthcare utilization by ASR under the terms of different local models (i.e., regular access equivalent to $\mathrm{SH}, \mathrm{EHC}$, and $\mathrm{HV}$ ).
\end{abstract}

Methods: We used data from three population-based, cross-sectional surveys among newly arrived ASR ( $N=863$ ) and analyzed six outcome measures: specialist and general practitioner (GP) utilization, unmet needs for specialist and GP services, emergency department use and avoidable hospitalization. Using logistic regression, we calculated odds ratios (OR) and 95\% confidence intervals for all outcome measures, while considering need by adjusting for sociodemographic characteristics and health-related covariates.

Results: Compared to ASR with regular access, ASR under the HV model showed lower needs-adjusted odds of specialist utilization ( $\mathrm{OR}=0.41$ [0.24-0.66]) while ASR under the EHC model did not differ from ASR with regular access in any of the outcomes. The comparison between EHC and HV model showed higher odds for specialist utilization under the $E H C$ model as compared to the HV model $(\mathrm{OR}=2.39$ [1.03-5.52]). GP and emergency department utilization, unmet needs and avoidable hospitalization did not show significant differences in any of the fully adjusted models.

Conclusion: ASR using the HV are disadvantaged in their access to healthcare compared to ASR having either an EHC or regular access. Given equal need, they use specialist services less. The identified inequalities constitute inequities in access to healthcare that could be reduced by policy change from HV to the EHC model during the initial 18 months waiting time, or by granting ASR regular healthcare access upon arrival. Potential patterns of differences in GP utilization, unmet needs, emergency department use and avoidable hospitalization between the models deserve further exploration in future studies.

\footnotetext{
*Correspondence: kayvan.bozorgmehr@uni-bielefeld.de

${ }^{1}$ Present Address: Department of Population Medicine and Health

Services Research, School of Public Health, Bielefeld University, PO Box 10

01 31, 33501 Bielefeld, Germany

Full list of author information is available at the end of the article
}

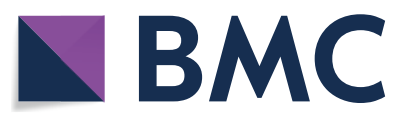

(c) The Author(s) 2022. Open Access This article is licensed under a Creative Commons Attribution 4.0 International License, which permits use, sharing, adaptation, distribution and reproduction in any medium or format, as long as you give appropriate credit to the original author(s) and the source, provide a link to the Creative Commons licence, and indicate if changes were made. The images or other third party material in this article are included in the article's Creative Commons licence, unless indicated otherwise in a credit line to the material. If material is not included in the article's Creative Commons licence and your intended use is not permitted by statutory regulation or exceeds the permitted use, you will need to obtain permission directly from the copyright holder. To view a copy of this licence, visit http://creativecommons.org/licenses/by/4.0/. The Creative Commons Public Domain Dedication waiver (http://creativeco mmons.org/publicdomain/zero/1.0/) applies to the data made available in this article, unless otherwise stated in a credit line to the data. 
Keywords: Access to healthcare, Health inequalities, Refugees, Asylum seekers, Healthcare utilization, Unmet needs, Emergency department use, Avoidable hospitalization, Germany

\section{Background}

Providing access to healthcare for asylum seekers and refugees (ASR) is part of the receiving countries' legal responsibilities [1]. However, many countries restrict the access of newly arriving ASR to regular healthcare services [2]. This may hinder need-based healthcare utilization, impact the health of ASR, and lead to inequalities in health $[3,4]$. Monitoring access to healthcare of ASR is therefore an important public health task.

There are multiple ways of looking at access. Following Aday and Andersen [5], access to healthcare means that those "who need care get into the system" (p. 218). It can be measured as potential access [6], with a focus on availability of services and insurance coverage. However, this tells us little about the actual utilization and ignores the impact of social determinants beyond health system characteristics on healthcare utilization [7, 8]. Alternatively, access can be equated with realized access [6]. It can then be conceptualized as actual use of healthcare services (using utilization indicators) or as non-realized access (using outcome indicators like forgone care and unmet needs) [9]. Further measures include ambulatory care sensitive hospitalization, which measures the lack of timely provision of ambulatory treatment leading to a potentially avoidable hospitalization [10].

When looking at determinants of realized access to healthcare among newly arriving ASR, the legal framework must be considered. In Germany, newly arriving asylum seekers are excluded from statutory health insurance (SHI). Their health entitlements are regulated by the asylum seekers' benefits act (in German: Asylbewerberleistungsgesetz (AsylbLG)), which is a federal law. Compared to SHI, the AsylbLG grants only a limited scope of healthcare during the first 18 months (15 months at time of data collection) or until a permanent protection status (refugee status or subsidiary protection) has been granted. The restricted entitlements include healthcare in case of acute illnesses and pain, preventive services and vaccines, and services related to pregnancy and birth (AsylbLG Art. 4). Access to further, mostly specialized, services can be granted on a case-bycase basis (AsylbLG Art. 6).

Given Germany's federal structure and decentralized governance, the local governments and social welfare offices (SWO) are responsible for implementing the AsylbLG, and thus for organizing access to healthcare for ASR [11]. Different policy choices on state and local levels have led to two different access models being applied across Germany to implement the AsylbLG during the waiting period: the healthcare voucher (in the following: $\mathrm{HV}$ ) and the electronic health card (in the following: EHC) $[12,13]$.

After the 18 months waiting period, asylum seekers under the AsylbLG are entitled to a scope of healthcare that is equivalent to SHI (AsylbLG Art. 2). Upon obtaining temporary or permanent legal status (before or after completion of 18 months), refugees have access to healthcare via SHI membership [11]. In both cases, they use a health insurance card to access health services. Hence, in practice, both recognized refugees and asylum seekers after 18 months in Germany have regular access, i.e. SHIor SHI-equivalent entitlements to healthcare. For the purpose of our study, we thus distinguish between three different access models (c. Table 1):

(1) Healthcare vouchers (HVs), which allow for healthcare access during the first 18 months in Germany. HVs are issued by the local SWO and entitlements are restricted (AsylbLG Art. 4 and 6). The paper-based HVs are usually valid for three months, or a single visit to a healthcare provider, and to be used within the respective administrative district. They are deposited with one service provider per calendar quarter, and each referral necessitates the

Table 1 Overview of access policies for asylum seekers and refugees in Germany

\begin{tabular}{llll}
\hline Access Policies & Health care voucher & $\begin{array}{l}\text { Eletronic health card upon } \\
\text { arrival }\end{array}$ & Regular access \\
\hline $\begin{array}{lll}\text { Duration of stay } \\
\text { State of the asy- }\end{array}$ & Ongoing & $\leq 18$ Months & $>18$ Months \\
$\begin{array}{l}\text { lum application } \\
\text { Entitlement }\end{array}$ & Restricted (Art. 4 and 6 AsylbLG) & Restricted (Art. 4 and 6 AylbLG) & $\begin{array}{l}\text { No restrictions, equivalent to social health insurance } \\
\text { (Art. 2 AsylbLG) }\end{array}$ \\
Federal State & Baden-Württemberg & Berlin & Baden-Württemberg and Berlin
\end{tabular}


approval and dispensation of another HV by the local SWO [11].

(2) Electronic health cards (EHCs), which allow for healthcare access during the first 18 months in Germany. The EHCs are issued by a local statutory health insurance (SHI) fund, but financed by the SWOs. Entitlements are restricted (AsylbLG Art. 4 and 6). The EHC is issued once and then usually valid for the whole period of restricted entitlements. It has a digital record of patient details and stays with the patient. Though EHC holders do not become members of the SHI, the SHI carries out billing and accounting procedures against an administrative fee.

(3) Irrespective of the access model used during the 18 months waiting period (HV or EHC), restrictions on healthcare entitlements and access are lifted after 18 months by granting SHI-equivalent health benefits (regulated by the AsylbLG Art. 2 and financed through the SWOs); or earlier if full SHI membership is granted through a temporary or permanent residence permit (regular access) [13-16].

The choice of the access model during the first 18 months - HV oder EHC - has been subject to controversial political debates. Proponents of the EHC model claim that it reduces discrimination against ASR, facilitates need-based healthcare utilization and reduces the administrative workload for welfare offices and service providers. Proponents of the HV model caution that the EHC model will lead to excessive healthcare utilization and thereby increase expenses $[13,17,18]$.

So far, there is limited evidence on the impact of the local policy model on access to healthcare. Qualitative studies suggest that the HVs are difficult to handle for healthcare users and providers and thereby hamper access to health services [18-21]. Quantitative studies provide further evidence for the disadvantages of the HV and of the entitlement restrictions during the 18-month waiting period; for instance, in terms of higher medical costs [22-25]. So far, there is no quantitative evidence of inequalities in access to healthcare among ASR who are subject to the three different access models. The aim of our research was therefore to analyze if different access models (HV, EHC, regular access) are associated with inequalities in access to healthcare understood as realized access or forgone care.

\section{Methods}

\section{Design, sampling, and population}

We used data from three population-based, cross-sectional surveys among newly arrived ASR $(\mathrm{N}=863)$ living in accommodation or reception centres in the states of Baden-Württemberg (BW) and Berlin (BE). In BE, the EHC was introduced in 2016; whereas in BW, all municipalities use HVs [11]. Sampling, recruitment, and survey instruments were nearly identical in both states [26, 27]. Around $3 \%$ of all 2,017 accommodation centres across the two states $(\mathrm{n}=81)$ were selected using random sampling and all adult residents of these centres (census approach) were invited to participate in the survey. In addition, six reception centres from BW were purposively selected for inclusion, with $25 \%$ of residents selected by random sampling and invited to participate. The overall response rate was $30.5 \%$ (see additional file 1). Questionnaires were developed from standardised, international survey instruments. They covered health status, access to and utilization of health services and socio-demographic aspects. Participants filled out a paper questionnaire in one of nine languages. Data collection for the majority of respondents ( $96 \%$ of the sample) took place between January 2018 and November 2018, while less than 4\% of participants (32 persons) were recruited in December 2019 . The study design, sampling procedure and data collection process have been described in more detail elsewhere $[26,27]$.

\section{Outcome measures}

A wide range of utilization (or process) indicators have been suggested to measure realized access $[6,7]$. While utilization indicators are important to detect barriers and assess equity in access to health services, utilization is not always an aim in itself [8]. Therefore, in addition to utilization indicators, outcome indicators related to the health consequences of service utilization (vs. forgone or delayed care) are also commonly included in the measurement of access. Subjective unmet needs and avoidable hospitalizations are two important outcome indicators that are internationally used to this end [10, 28]. They have been adapted to the German context $[29,30]$ and to refugee populations in Germany in particular [31-33]. Subjective unmet need describes a situation in which healthcare was not sought despite subjectively felt need [28]. Avoidable hospitalization can be defined as hospital admissions for conditions for which hospitalization can be prevented by providing timely and adequate treatment in the outpatient setting. These conditions are defined as ambulatory care-sensitive conditions (ACSC) [10].

To analyse differences in access to healthcare, we included three utilization and three outcome indicators. As utilization indicators we included self-reported utilization of general practitioner (GP) and specialist services in the last four weeks $(\mathrm{y} / \mathrm{n})$ and of emergency departments in the last 12 months $(\mathrm{y} / \mathrm{n})$. As outcome indicators we included hospital admissions for ACSC in the last 12 
months $(\mathrm{y} / \mathrm{n})$ and subjective unmet needs for specialist or GP services in the last 12 months $(\mathrm{y} / \mathrm{n})$. ACSC were assessed using two questions: first, participants were asked whether they had one of the conditions identified as ACSC by Sundmacher et al. [29] in the last 12 months (see additional file 2). Second, they were asked whether they had been hospitalized for any of the said conditions. To assess unmet needs, participants were asked directly if they had refrained from seeking healthcare despite the subjectively felt need to see a doctor.

\section{Exposures and Co-variables}

The access model used - HV, EHC or regular access was set as the exposure. It was directly assessed for the state of BW. For BE, all persons with a duration of stay of more than 15 months or with a secured residence status (refugee status or subsidiary status) were coded as having regular access, while all others were considered using an EHC. It is important to note that this "waiting period" was extended from 15 to 18 months in August 2019. That is, at the time of data collection, restricted health entitlements applied during asylum seekers' first 15 months in Germany. For this reason, we used a duration of stay of 15 months as a cut-off date in our data analysis.

A conceptual approach to identifying major determinants of health service utilization and to differentiating between determinants of inequalities in realized access has been developed by Andersen and colleagues. They distinguish between predisposing characteristics (e.g., age, sex, socioeconomic status) and enabling resources which are related to the health system (e.g., health policy, financing, organization, resources, and availability of services). Given the importance of the actual health status and related healthcare needs as a major determinant of healthcare utilization, it is essential to include the actual health status in our analyses to approximate and adequately adjust for underlying healthcare needs in the study population $[5,6,34]$. We therefore included major predisposing characteristics (age, sex, region of origin, duration of stay in Germany, accommodation type and education) and important need- and health-related information (subjective health, chronic illness, and having a regular GP) as covariates.

In order to consider differences in access related to geographical factors, like urban-rural characteristics, we performed a sensitivity analysis by adjusting all full models additionally for urbanity. Districts with a population density below 150 inhabitants per $\mathrm{km}^{2}$ were categorised as rural, those with higher density as urban, following the definition of the Federal Institute for Research on Building, Urban Affairs and Spatial Development (BBSR )[35]. As $\mathrm{BE}$ is considered as urban in its entirety, the approach primarily controlled for variations in access between rural areas in the state of $\mathrm{BW}$ and urban areas in $\mathrm{BW}$ and $\mathrm{BE}$.

\section{Statistical analysis}

We used logistic regression to calculate odds ratios (OR) for all outcomes, adjusting for socio-demographic characteristics (age, sex, region of origin, duration of stay in Germany, accommodation type and education) and health-related covariates (subjective health, chronic illness and having a regular GP) which we identified as potential confounders. Having regular access - as compared to access via EHC or HV - was chosen as a reference category. Based on the literature, this was considered the best possible access option. In addition, the HV model was also used as reference category repeating the same regression analyses for all outcomes. This allowed for a direct comparison of differences in access between the HV and EHC model.

All analyses were weighted (using design and calibration weights), treating reception centres in BW, accommodation centres in BW, and accommodation centres in BE each as separate clusters (see additional file 3). Calibration was conducted using data from the statistical offices in BW and BE for age, sex and region of origin $[36,37]$. Missing values did not show systematic patterns related to the outcome and were thus assumed to be missing at random. For outcome and exposure indicators, missing values were imputed using single imputation according to the R-package mice [38] (see additional file 4). To understand the sensitivity of our results to weighting, the design effect (DEFF) was calculated. Low DEFF indicate small weighting effects. The overall model fit comparing the differences between observed and expected values for the Null-model and the full model was assessed using an adapted F-test for weighted survey designs. Larger F-values with non-significant p-values $(>0.05)$ indicate better model fit [39].

\section{Results \\ Descriptive results}

The sample includes responses from 863 individuals of which 560 were living in the state of BW and 303 in the state of BE. Of the 560 participants in BW, 250 (44.6\%) were using the HV model and $240(42.7 \%)$ reported regular access. For 70 individuals (12.5\%), information on the access model was missing. In Berlin, 49 (16.2\%) were using the EHC model and 227 (74.9\%) were having regular access while information on the access model was missing for 27 participants (8.9\%).

There were no significant differences in age, sex, educational score or health status (subjective health or chronic illnesses) between persons subject to different access models. Given the requirements for regular 
access (either duration of stay of more than 15 months at the time of data collection or refugee status), duration of stay and residence status are highly associated with the access model. The region of origin is also significantly associated with the access model (c. Tab. 2 for details).

Of all participants, $29 \%$ indicated having used specialist services and $43.3 \%$ reported having seen a GP in the last four weeks. There was a considerable difference between the states for specialist utilization with only $24.1 \%$ reporting a visit to a specialist in BW compared to $38 \%$ in BE. We found no substantial differences in emergency department use, subjective unmet needs of specialist and GP services, and avoidable hospitalization. In total, $27.9 \%$ reported at least one visit to the emergency department, $26 \%$ and $26.7 \%$ reported unmet needs for specialist and GP services respectively, and $21.3 \%$ reported at least one avoidable hospitalization in the last 12 months. The share of missing information was rather high for specialist utilization (24.1\%), but also for GP utilization (18.1\%) and unmet needs (19.7\% and $18.7 \%$ ), while it was only $10.7 \%$ for emergency department use and $7.1 \%$ for avoidable hospitalization (c. Tab. 3).

\section{Inequalities in access comparing $\mathrm{HV}$ and $\mathrm{EHC}$ with regular access}

ASR under the HV model were less likely to use specialist $(\mathrm{OR}=0.46[0.31-0.70])$ or GP $(\mathrm{OR}=0.57$ [0.340.95]) services compared to ASR with regular access while adjusting for age and sex. This difference is significant based on the 95\%-CI. For the other outcomes, no significant differences could be observed between both groups.

ASR under the EHC model were more likely to report unmet needs for specialist services $(\mathrm{OR}=2.11$ [1.323.40]) compared to ASR with regular access while adjusting for age and sex. No significant difference was found for GP and specialist utilization, GP unmet needs, avoidable hospitalization, and emergency department visits between the two groups (c. Fig. 1).

The final models were adjusted for health status, duration of stay, region of origin, educational score, having a regular GP and accommodation type. Their results were similar to those of the simple models. ASR under the $\mathrm{HV}$ model showed lower odds of specialist utilization $(\mathrm{OR}=0.41$ [0.24-0.66]) compared to ASR with regular access. For all other indicators, there was no difference between HV users and ASR with regular access.

ASR under the EHC model did not show any statistically significant differences (c. Fig. 2).

\section{Inequalities in access comparing the $\mathrm{HV}$ and the EHC model}

The comparison of access between the two models that apply during the 15 months waiting period showed higher odds for specialist utilization $(\mathrm{OR}=1.93$ [1.013.69]) and specialist unmet needs $(\mathrm{OR}=1.94$ [1.133.31]) among ASR under the EHC model compared to ASR under the HV model, adjusting for age and sex. For the remaining four outcomes, odds among ASR with a EHC were also higher compared to odds among ASR with HVs. However, given wide confidence intervals that include the value one, they do not indicate significant differences (c. Fig. 3).

After adjustment for health status and other potential confounders the odds for specialist utilization in the last four weeks were still significantly higher under the EHC model $(\mathrm{OR}=2.39$ [1.03-5.52]) as compared to the HV model. Odds of GP utilization (OR $=2.18$ [0.805.92]), specialist unmet needs $(\mathrm{OR}=2.01[0.97-4.19])$, emergency department use $(\mathrm{OR}=1.35$ [0.66-2.76]) and avoidable hospitalization $(\mathrm{OR}=1.77$ [0.77-4.07]) showed higher point-estimates under the EHC model compared to the HV model. However, 95\%-confidence intervals suggest that all differences were not statistically significant (c. Fig. 4).

Overall model-fit was acceptable with non-significant F-tests for nearly all final models (range of $p$-values between 0.420 and 0.849; exception: $p<0.001$ for avoidable hospitalization). Analysis of the design effects for the final regression models (range of DEFF between 0.993 and 2.520) showed a moderate influence of weighting on the results, which stresses the importance of weighting for valid and generalizable results. However, the comparison of ORs between weighted and non-weighted results did not reveal major differences for any of the outcomes (see Additional files 5, 6, $7,8,9$ ). The results of the sensitivity analysis (controlling for urbanity) did neither lead to any considerable changes of the results in terms of magnitude or direction of estimates or statistical significance (Additional Files 10-11), nor did it improve the overall model fit (data not shown).

\section{Discussion}

Our study is the first comparison of realized access to healthcare between the three different access models for ASR in Germany. It thus adds important empirical knowledge to the current literature on access to healthcare among ASR. Our results show significant differences for specialist service utilization between the access models. ASR under the HV model reported lower needsadjusted utilization of specialist services compared to 
Table 2 Socio-demographic and health-related information of the sample according to access model

\begin{tabular}{|c|c|c|c|c|c|c|c|c|c|c|c|c|}
\hline & \multicolumn{2}{|c|}{ HV (BW) } & \multicolumn{2}{|c|}{ EHC (BE) } & \multicolumn{2}{|c|}{$\begin{array}{l}\text { Regular access in BW } \\
\text { (after HV use) }\end{array}$} & \multicolumn{2}{|c|}{$\begin{array}{l}\text { Regular access in BE } \\
\text { (after EHC use) }\end{array}$} & \multicolumn{2}{|c|}{ Missing } & \multicolumn{2}{|c|}{ Total } \\
\hline & $\mathrm{N}$ & $\%$ & $\mathrm{~N}$ & $\%$ & $\mathrm{~N}$ & $\%$ & $\mathrm{~N}$ & $\%$ & $\mathrm{~N}$ & $\%$ & $\mathrm{~N}$ & $\%$ \\
\hline Total & 250 & 100 & 49 & 100 & 240 & 100 & 227 & 100 & 97 & 100 & 863 & 100 \\
\hline \multicolumn{13}{|l|}{ Age at interview } \\
\hline $18-25$ & 80 & 32 & 9 & 18.4 & 72 & 30 & 47 & 20.7 & 15 & 15.5 & 223 & 25.8 \\
\hline $26-30$ & 42 & 16.8 & 7 & 14.3 & 35 & 14.6 & 35 & 15.4 & 12 & 12.4 & 131 & 15.2 \\
\hline $31-35$ & 41 & 16.4 & 8 & 16.3 & 39 & 16.3 & 30 & 13.2 & 8 & 8.2 & 126 & 14.6 \\
\hline $36-40$ & 31 & 12.4 & 7 & 14.3 & 34 & 14.2 & 28 & 12.3 & 4 & 4.1 & 104 & 12.1 \\
\hline $41+$ & 32 & 12.8 & 8 & 16.3 & 49 & 20.4 & 49 & 21.6 & 5 & 5.2 & 143 & 16.6 \\
\hline Missing & 24 & 9.6 & 10 & 20.4 & 11 & 4.6 & 38 & 16.7 & 53 & 54.6 & 136 & 15.8 \\
\hline \multicolumn{13}{|l|}{ Sex } \\
\hline Male & 168 & 67.2 & 23 & 46.9 & 155 & 64.6 & 138 & 60.8 & 33 & 34 & 517 & 59.9 \\
\hline Female & 69 & 27.6 & 17 & 34.7 & 76 & 31.7 & 70 & 30.8 & 17 & 17.5 & 249 & 28.9 \\
\hline Missing & 13 & 5.2 & 9 & 18.4 & 9 & 3.8 & 19 & 8.4 & 47 & 48.5 & 97 & 11.2 \\
\hline \multicolumn{13}{|l|}{ Educational score* } \\
\hline Low & 57 & 22.8 & 9 & 18.4 & 64 & 26.7 & 66 & 29.1 & 14 & 14.4 & 210 & 24.3 \\
\hline Medium & 80 & 32 & 16 & 32.7 & 84 & 35 & 69 & 30.4 & 13 & 13.4 & 262 & 30.4 \\
\hline High & 52 & 20.8 & 11 & 22.4 & 34 & 14.2 & 46 & 20.3 & 8 & 8.2 & 151 & 17.5 \\
\hline Missing & 61 & 24.4 & 13 & 26.5 & 58 & 24.2 & 46 & 20.3 & 62 & 63.9 & 240 & 27.8 \\
\hline \multicolumn{13}{|l|}{ Region of origin ${ }^{* * *}$} \\
\hline Eastern Europe & 6 & 2.4 & 0 & 0 & 5 & 2.1 & 9 & 4 & 1 & 1 & 21 & 2.4 \\
\hline Southern Europe & 12 & 4.8 & 1 & 2 & 5 & 2.1 & 5 & 2.2 & 1 & 1 & 24 & 2.8 \\
\hline Western Asia & 59 & 23.6 & 21 & 42.9 & 65 & 27.1 & 93 & 41 & 19 & 19.6 & 257 & 29.8 \\
\hline Southern Asia & 42 & 16.8 & 7 & 14.3 & 77 & 32.1 & 82 & 36.1 & 15 & 15.5 & 223 & 25.8 \\
\hline Western Africa & 75 & 30 & 1 & 2 & 33 & 13.8 & 2 & 0.9 & 12 & 12.4 & 123 & 14.3 \\
\hline Central Africa & 5 & 2 & 0 & 0 & 8 & 3.3 & 1 & 0.4 & 1 & 1 & 15 & 1.7 \\
\hline Northern Africa & 3 & 1.2 & 0 & 0 & 0 & 0 & 1 & 0.4 & 0 & 0 & 4 & 0.5 \\
\hline Other & 31 & 12.4 & 14 & 28.6 & 38 & 15.8 & 23 & 10.1 & 5 & 5.2 & 111 & 12.9 \\
\hline Missing & 17 & 6.8 & 5 & 10.2 & 9 & 3.8 & 11 & 4.8 & 43 & 44.3 & 85 & 9.8 \\
\hline \multicolumn{13}{|l|}{ Residence status ${ }^{* * *}$} \\
\hline Asylum seeker & 173 & 69.2 & 28 & 57.1 & 90 & 37.5 & 64 & 28.2 & 24 & 24.7 & 379 & 43.9 \\
\hline Asylum granted & 10 & 4 & 7 & 14.3 & 66 & 27.5 & 106 & 46.7 & 6 & 6.2 & 195 & 22.6 \\
\hline Toleration ('Duldung') & 16 & 6.4 & 4 & 8.2 & 24 & 10 & 14 & 6.2 & 2 & 2.1 & 60 & 7 \\
\hline Asylum status rejected & 28 & 11.2 & 2 & 4.1 & 22 & 9.2 & 20 & 8.8 & 3 & 3.1 & 75 & 8.7 \\
\hline Missing & 23 & 9.2 & 8 & 16.3 & 38 & 15.8 & 23 & 10.1 & 62 & 63.9 & 154 & 17.8 \\
\hline \multicolumn{13}{|c|}{ Time since arrival (months) $)^{* * *}$} \\
\hline $0-6$ & 115 & 46 & 16 & 32.7 & 24 & 10 & 5 & 2.2 & 8 & 8.2 & 168 & 19.5 \\
\hline 6-12 & 41 & 16.4 & 14 & 28.6 & 13 & 5.4 & 3 & 1.3 & 3 & 3.1 & 74 & 8.6 \\
\hline $13-15$ & 45 & 18 & 7 & 14.3 & 50 & 20.8 & 8 & 3.5 & 4 & 4.1 & 114 & 13.2 \\
\hline $16-24$ & 16 & 6.4 & 0 & 0 & 105 & 43.8 & 61 & 26.9 & 12 & 12.4 & 194 & 22.5 \\
\hline $24+$ & 2 & 0.8 & 3 & 6.1 & 25 & 10.4 & 90 & 39.6 & 2 & 2.1 & 122 & 14.1 \\
\hline Missing & 31 & 12.4 & 9 & 18.4 & 23 & 9.6 & 60 & 26.4 & 68 & 70.1 & 191 & 22.1 \\
\hline \multicolumn{13}{|l|}{ General health } \\
\hline Very good & 33 & 13.2 & 10 & 20.4 & 42 & 17.5 & 46 & 20.3 & 13 & 13.4 & 144 & 16.7 \\
\hline Good & 83 & 33.2 & 11 & 22.4 & 71 & 29.6 & 65 & 28.6 & 25 & 25.8 & 255 & 29.5 \\
\hline Fair & 73 & 29.2 & 21 & 42.9 & 72 & 30 & 60 & 26.4 & 18 & 18.6 & 244 & 28.3 \\
\hline Bad & 30 & 12 & 5 & 10.2 & 21 & 8.8 & 30 & 13.2 & 7 & 7.2 & 93 & 10.8 \\
\hline Very bad & 19 & 7.6 & 1 & 2 & 14 & 5.8 & 7 & 3.1 & 9 & 9.3 & 50 & 5.8 \\
\hline Missing & 12 & 4.8 & 1 & 2 & 20 & 8.3 & 19 & 8.4 & 25 & 25.8 & 77 & 8.9 \\
\hline \multicolumn{13}{|l|}{ Longstanding illness } \\
\hline No & 136 & 54.4 & 23 & 46.9 & 127 & 52.9 & 127 & 55.9 & 45 & 46.4 & 458 & 53.1 \\
\hline Yes & 99 & 39.6 & 23 & 46.9 & 90 & 37.5 & 78 & 34.4 & 23 & 23.7 & 313 & 36.3 \\
\hline Missing & 15 & 6 & 3 & 6.1 & 23 & 9.6 & 22 & 9.7 & 29 & 29.9 & 92 & 10.7 \\
\hline
\end{tabular}


Table 3 Utilization and outcome measures according to state

\begin{tabular}{|c|c|c|c|c|c|c|}
\hline & \multicolumn{2}{|c|}{ Baden-Württemberg } & \multicolumn{2}{|c|}{ Berlin } & \multicolumn{2}{|c|}{ Total } \\
\hline & $\mathbf{N}$ & $\%$ & $\mathbf{N}$ & $\%$ & $\mathbf{N}$ & $\%$ \\
\hline \multicolumn{7}{|c|}{ Specialist utilization last 4 weeks ${ }^{* * *}$} \\
\hline No & 284 & 50.7 & 121 & 39.9 & 405 & 46.9 \\
\hline Yes & 135 & 24.1 & 115 & 38 & 250 & 29 \\
\hline Missing & 141 & 25.2 & 67 & 22.1 & 208 & 24.1 \\
\hline \multicolumn{7}{|c|}{ GP utilization last 4 weeks } \\
\hline No & 226 & 40.4 & 107 & 35.3 & 333 & 38.6 \\
\hline Yes & 236 & 42.1 & 138 & 45.5 & 374 & 43.3 \\
\hline Missing & 98 & 17.5 & 58 & 19.1 & 156 & 18.1 \\
\hline \multicolumn{7}{|c|}{ Specialist unmet need last 12 months } \\
\hline No & 310 & 55.4 & 159 & 52.5 & 469 & 54.3 \\
\hline Yes & 139 & 24.8 & 85 & 28.1 & 224 & 26 \\
\hline Missing & 111 & 19.8 & 59 & 19.5 & 170 & 19.7 \\
\hline \multicolumn{7}{|c|}{ GP unmet need last 12 months } \\
\hline No & 318 & 56.8 & 154 & 50.8 & 472 & 54.7 \\
\hline Yes & 144 & 25.7 & 86 & 28.4 & 230 & 26.7 \\
\hline Missing & 98 & 17.5 & 63 & 20.8 & 161 & 18.7 \\
\hline \multicolumn{7}{|c|}{ Emergency department visit last 12 months } \\
\hline No & 364 & 65 & 166 & 54.8 & 530 & 61.4 \\
\hline Yes & 149 & 26.6 & 92 & 30.4 & 241 & 27.9 \\
\hline Missing & 47 & 8.4 & 45 & 14.9 & 92 & 10.7 \\
\hline \multicolumn{7}{|c|}{ Avoidable hospitalization last 12 months } \\
\hline No & 393 & 70.2 & 225 & 74.3 & 618 & 71.6 \\
\hline Yes & 128 & 22.9 & 56 & 18.5 & 184 & 21.3 \\
\hline Missing & 39 & 7 & 22 & 7.3 & 61 & 7.1 \\
\hline Total & 560 & 100 & 303 & 100 & 863 & 100 \\
\hline
\end{tabular}

persons using the EHC and to persons with regular access.

The lower utilization of specialist services might be related to access barriers that are inherent to the $\mathrm{HV}$ model (such as the need for prior approval by the local welfare office for specialist utilization, or the limited validity of HVs to three months). For all other outcomes - GP utilization, unmet needs, emergency department use and avoidable hospitalization - differences between the groups were neither consistent nor significant in the fully adjusted models. Tendencies towards differences in GP utilization, specialist unmet needs and avoidable hospitalizations should be further explored.

Using data from three population based, multilingual surveys with tested items contributed to the validity of the results. It also enabled us to control for a wide range of socio-demographic health-related, and geographical confounders captured in the survey. The underlying survey data was adequate for our study as we used random sampling techniques, adaptive recruitment and surveying strategies to draw a comprehensive and reliable picture of health and healthcare access among ASR [26]. We obtained a response rate that was comparable to rates obtained in nationwide surveys of the general population (e.g. 35\% in the German Population Survey of the Social Sciences (ALLBUS), 42\% in the DEGS survey of the Robert Koch-Institute) [40, 41]. Furthermore, we performed state-of-the-art imputation of missing data to avoid bias through inappropriate use of complete case analyses (i.e. excluding participants with missing observations on given outcomes or co-variables).

Besides these strengths, there are important methodological implications of our research. First, there was a significant association between region of origin and access model. This is mainly explained by the fact that the country of origin influences the distribution of newcomers among states in Germany as well as their chances of obtaining permanent legal status. At the same time, it highlights the importance of controlling for region or country of origin when making 


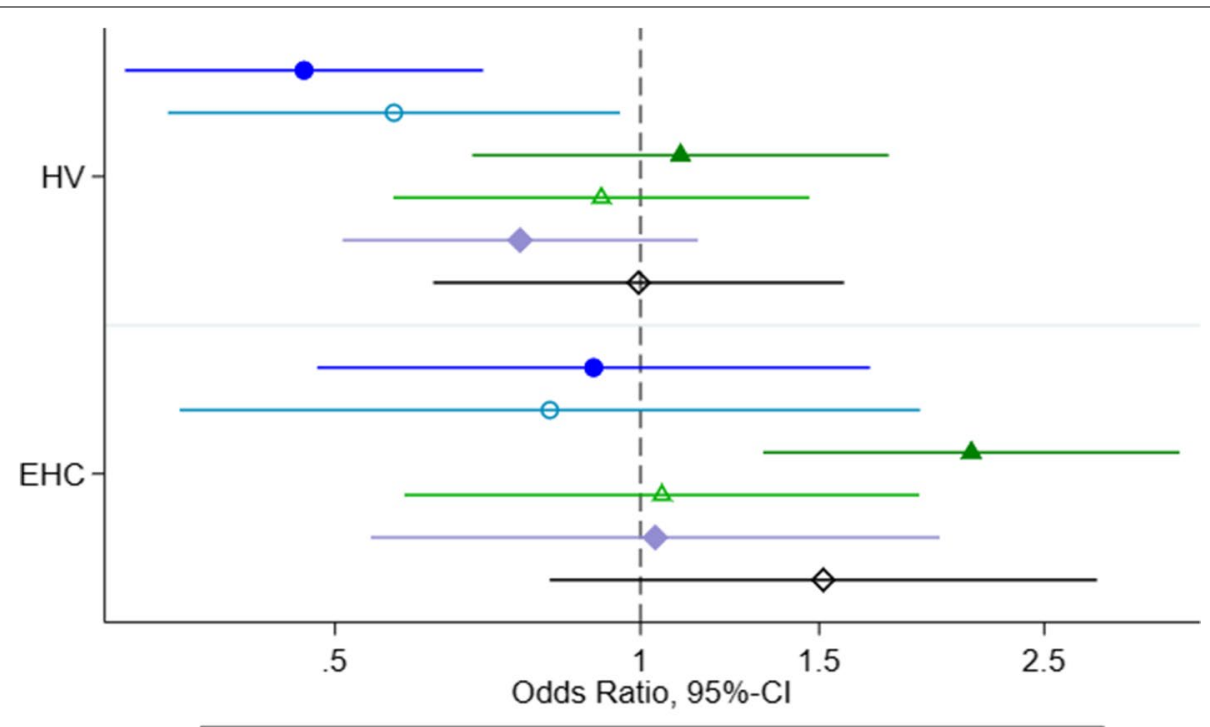

\begin{tabular}{|ll|}
\hline specialist use & $\bigcirc$ GP use \\
$\Delta$ specialist unmet needs & $\Delta$ GP unmet needs \\
emergency department use & $\diamond$ avoidable hospitalization
\end{tabular}

Fig. 1 Odds-Ratios (and 95\%-CIs) of access to healthcare comparing between access models, adjusted for age and sex (ref=regular access) Legend: $H V=$ Healthcare voucher; $E H C=$ electronic health card; $x$-axis with $95 \%$ confidence intervals on a log-scale

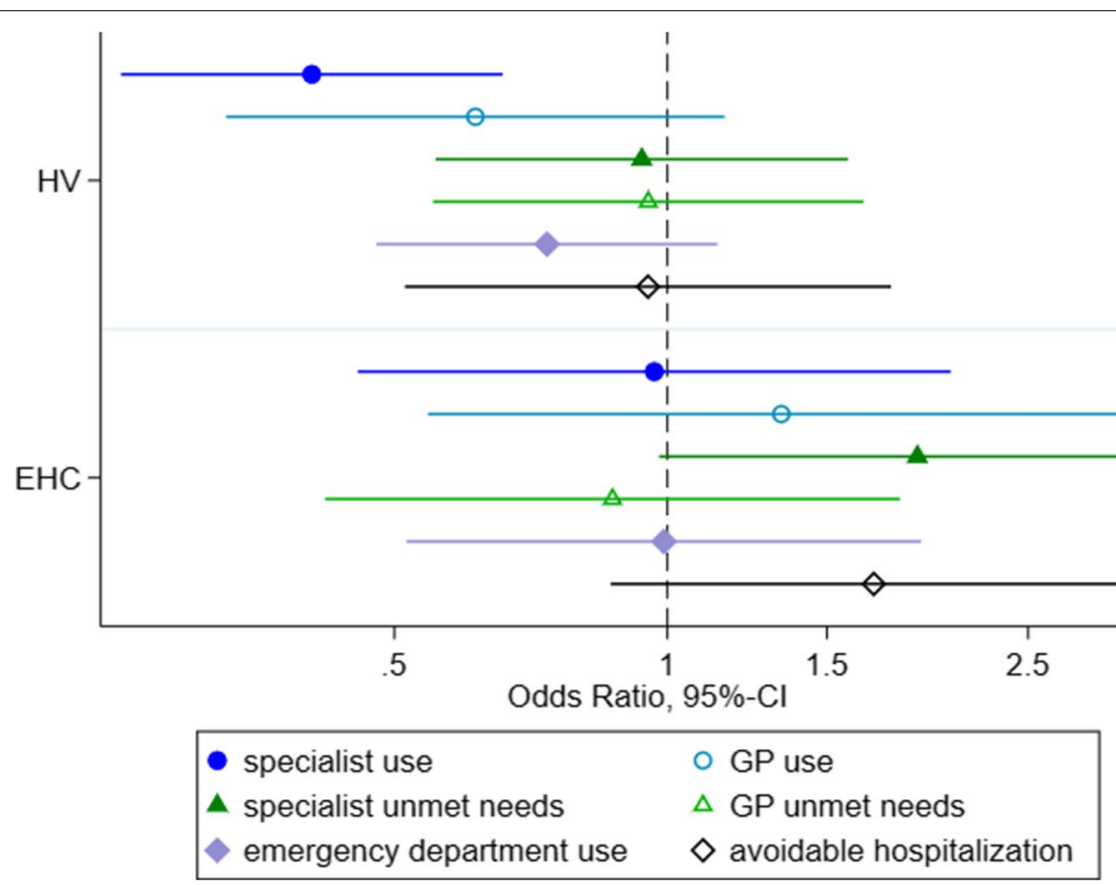

Fig. 2 Fully adjusted Odds-Ratios (and 95\%-Cls) of access to healthcare comparing between access models (ref=regular access) Legend: $\mathrm{HV}=$ Healthcare voucher; $\mathrm{EHC}=$ electronic health card; $x$-axis with $95 \%$ confidence intervals on a log-scale

comparisons between the German states. Second, to the best of our knowledge, this was the first time that avoidable hospitalizations were assessed in a survey design (and not through routine or claims data using ICD-codes). The approach turned out to be feasible and the comparatively low share of missing responses 


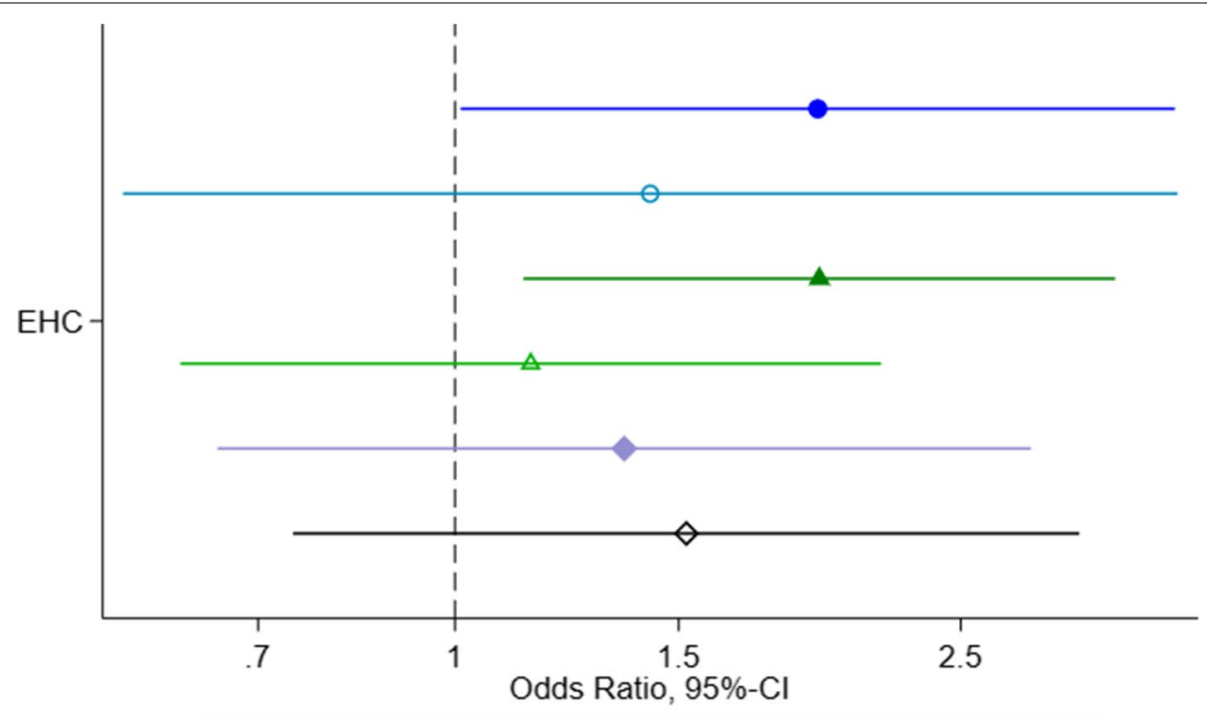
- specialist use
○ GP use
specialist unmet needs
$\triangle$ GP unmet needs
emergency department use
$\diamond$ avoidable hospitalization

Fig. 3 Odds-Ratios (and 95\%-Cls) of access to healthcare comparing between access models used in the first 15 months, adjusted for age and sex

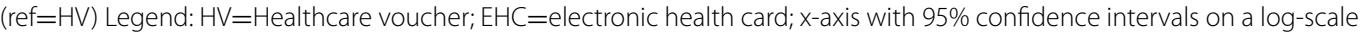

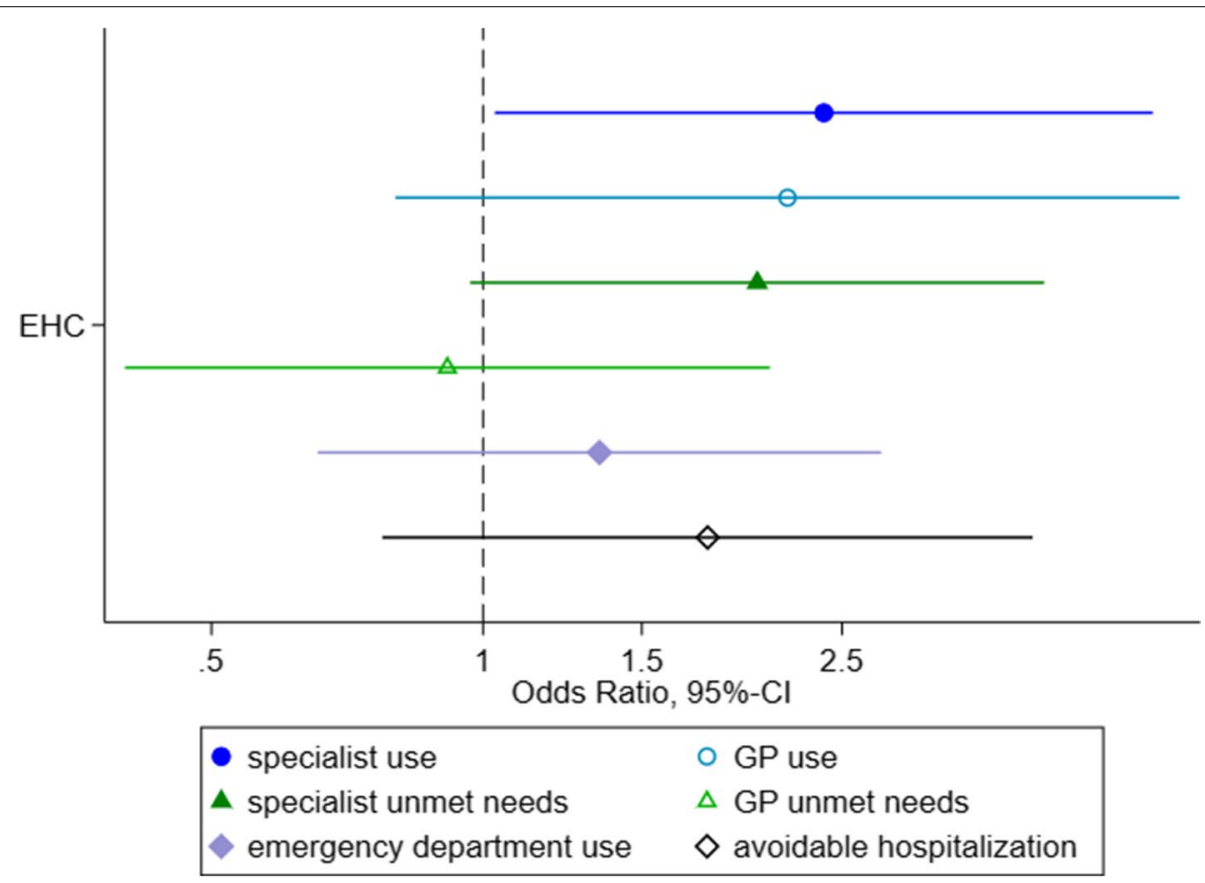

Fig. 4 Fully adjusted Odds Ratios (and 95\%-Cls) of access to healthcare comparing between access models used in the first 15 months (ref=HV)

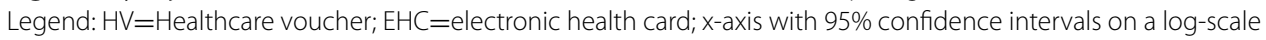

(only $7.1 \%$ ) showed a high acceptance among respondents. Future studies should further evaluate the item's validity and potential for use in future health surveys.
This is especially important for research on populations that tend to remain left out of routine data collection. 
Third, while the questions referring to specialist and GP service utilization referred to the last four weeks, questions related to all other outcomes referred to the last 12 months. This may have led to a recall bias as people are requested to report their health seeking behaviour for long periods of time. In addition, respondents potentially changed from one access model to another (from HV or EHC to regular access), resulting in misclassification bias. Thus, estimates for unmet needs, emergency department use and avoidable hospitalization are less robust than for specialist and GP utilization. The observed minor differences for these outcomes (e.g., for specialist unmet needs) are therefore not further interpreted. Finally, our data is from two different states with potentially unmeasured differences in availability of interpreters and organization of healthcare services. These unmeasured differences might constitute confounders especially for the comparison between $\mathrm{HV}$ and $\mathrm{EHC}$, as all included $\mathrm{HV}$ users lived in BW while all EHC users lived in $\mathrm{BE}$.

Our results are in line with qualitative studies that hypothesised lower utilization of outpatient services among HV users due to bureaucratic barriers [19, 20]. A quantitative analysis of claims data [23] and a regional survey [22] in the state of North Rhine Westphalia, too, have identified access barriers related to specialist utilization, which ultimately led to inequalities in healthcare utilization. There is thus reason to suspect that persons who are subject to the HV model have lower access to specialist services compared to EHC users and people with regular access, while having equivalent needs. According to the literature on health inequalities this would constitute a violation of the principle of horizontal equity (equal access for equal needs) [42]. We did not find inequalities related to unmet needs, emergency department use and avoidable hospitalization. Other studies reported significant differences for these outcomes; for example, higher rates of avoidable hospitalizations among EHC users as compared to persons with regular access [32], and higher emergency department use under the $\mathrm{HV}$ model as compared to the EHC model [23]. We could not back up these findings with our analyses, which may be due to the abovementioned methodological limitations.

The results of our study have important implications for the controversial debate on the choice of access model for ASR during their first 18 months in Germany. The identified inequalities in access to specialist and GP services provide further evidence for the advantages of the EHC model compared to the $\mathrm{HV}$ model. The EHC model facilitates need-based healthcare utilization by providing access similar to the regular access model. Those local governments that, nonetheless, adhere to the HV model often justify their policy decision with cost arguments; that is, with the assumption that the EHC model would lead to excessive utilization of healthcare and thereby increase health expenses [43]. Given that recent studies refute such cost arguments [24, 44], little evidence-based arguments are left to justify upholding the HV model. In that light, policymakers who have so far opted for the $\mathrm{HV}$ model may want to reconsider introducing the EHC (or disclose the remaining reasons for not doing so). The relevance of such policy change has increased lately, as in August 2019 the waiting period during which the respective access models (HV and EHC) apply has been prolonged from 15 to 18 months [11].

While this study looked at the direct effects of the different models on access, we were unable to analyse long-term effects of lower healthcare utilization among HV users on their health status. Longitudinal studies will be needed to study the health consequences of the different access models. Such studies could revisit analyses of avoidable hospitalizations, emergency department use and unmet needs, as methodological limitations impeded a thorough analyses of these aspects in our study.

\section{Conclusion}

ASR who are subject to the HV model are disadvantaged in their access to healthcare. With equal need, they use specialist services less often than ASR with an EHC and those with regular access. The identified inequalities constitute inequities in access to healthcare that could be reduced by policy change from $\mathrm{HV}$ to the EHC model (or by granting regular access upon arrival). The EHC model ensures access to GP and specialist services comparable to regular access as there are no significant differences in outpatient care utilization between ASR with EHC and ASR with regular access. Interpretation of the results for unmet needs, emergency department use and avoidable hospitalization is limited due to methodological constrains. Still, the respective patterns of difference that were observed deserve further exploration in future studies.

\section{Abbreviations}

ACSC: Ambulatory care sensitive conditions; ASR: Asylum seekers and refugees; AsylbLG: Asylbewerberleistungsgesetz/Asylum Seeker's Benefits Act; BW: BadenWuerttemberg; BE: Berlin; DEFF: Design effect; EHC: Electronic health card; GP: General practitioner; HV: Healthcare voucher; SWO: Social welfare office. 


\section{Supplementary Information}

The online version contains supplementary material available at https://doi. org/10.1186/s12939-021-01607-y.

\section{Additional file 1. \\ Additional file 2 . \\ Additional file 3. \\ Additional file 4 \\ Additional file 5 . \\ Additional file 6. \\ Additional file 7. \\ Additional file 8. \\ Additional file 9. \\ Additional file 10 .}

Additional file 11.

\section{Acknowledgements}

The authors would like to thank all study participants for their valuable time and efforts.

LB and KB would like to thank the Association of Districts (Landkreistag) of Baden-Württemberg, the district authorities all 44 districts responsible for reception of ASR, the Ministry of Social Affairs and Integration BadenWürttemberg, the Ministry of the Interior, Digitalization and Migration Baden-Württemberg, and the responsible regional councils of the state of Baden-Württemberg for supporting the study.

NG would like to thank those students of the Berlin School of Public Health, who were involved in the Berlin-based data collection for this study; and she is indebted to the Berlin Senate Administration, the Berlin Office for Refugee Affairs, and the managers and staff of the included accommodation centres for supporting this research.

\section{Authors' contributions}

$\mathrm{LB}$ and $\mathrm{KB}$ conceived the study and were responsible for instrument development and sampling approach across both study sites, as well as data collection and methodology in Baden-Württemberg. NG was responsible for data collection and methodology in Berlin. JW and KB conceptualized the analysis plan. JW conducted the analysis and drafted the first version of the manuscript. LB was responsible for data management and contributed significantly to the formal analysis. LB, NG and KB revised the manuscript critically for important intellectual content. All authors read and approved the final manuscript.

\section{Funding}

Open Access funding enabled and organized by Projekt DEAL.This study received funding by the German Federal Ministry for Education and Research (BMBF) in the scope of the project RESPOND (Grant Number: 01GY1611, Grant Recipient: KB). The funder had no influence on study design, analysis or decision to publish. Further funding was received by the People Programme (Marie Curie Actions) of the European Union's Seventh Framework Programme (FP7/20072013) under REA grant agreement no. 600209 (TU Berlin/IPODI) (Grant recipient: NG).

\section{Availability of data and materials}

The datasets used during the current study are available from https://respondstudy.org/en/resources/ on reasonable request to the corresponding author.

\section{Declarations}

Ethics approval and consent to participate

The study has been positively reviewed by the Ethics Committee of the Charité University Hospital Berlin (EA4/111/18), and the ethics committee of the Medical Faculty Heidelberg (S-516/2017)

\section{Consent for publication}

Not applicable

\section{Competing interests}

The authors declare that they have no competing interests.

\section{Author details}

${ }^{1}$ Present Address: Department of Population Medicine and Health Services Research, School of Public Health, Bielefeld University, PO Box 1001 31, 33501 Bielefeld, Germany. ${ }^{2}$ Section for Health Equity Studies and Migration, Department of General Practice and Health Services Research, University Hospital Heidelberg, Im Neuenheimer Feld 130.3, 69120 Heidelberg, Germany. ${ }^{3}$ Department of Health Care Management $(\mathrm{H} 80)$, Technical University Berlin, Strasse des 17. Juni 135, 10623 Berlin, Germany.

Received: 26 January 2021 Accepted: 10 December 2021

Published online: 24 January 2022

\section{References}

1. The European Parliament and the Council of the European Union. Directive 2013/33/EU of 26 June 2013 laying down standards for the reception of applicants for international protection. 2013.

2. International Organization for Migration (IOM) Regional Office Brussels. Migration Health Division (MHD). Summary Report on the MIPEX Health Strand and Country Reports. Geneva: International Organization for Migration (IOM); 2016. http://members.costadapt.eu/images/3/33/ MIPEX_11_June_final.pdf.

3. Bradby $H$, Humphris $R$, Newall D, Phillimore J. Public health aspects of migrant health: a review of the evidence on health status for refugees and asylum seekers in the European Region. 2015. http://www.euro.who. int/_data/assets/pdf_file/0004/289246/WHO-HEN-Report-A5-2-Refug ees_FINAL.pdf?ua=1. Accessed 18 Sep 2020.

4. Thiel de Bocanegra H, Carter-Pokras O, Ingleby JD, Pottie K, Tchangalova $\mathrm{N}$, Allen SI, et al. Addressing refugee health through evidence-based policies. Ann Epidemiol. 2018:28:411-9.

5. Aday LA, Andersen R. A framework for the study of access to medical care. Health Serv Res. 1974:9:208-20.

6. Andersen RM. Revisiting the Behavioral Model and Access to Medical Care : Does it Matter? J Health Soc Behav. 1995;36:1-10

7. Committee on Monitoring Access to Personal Health Care Services - Institute of Medicine. In: Access to Health Care in America. Washington D.C.: National Academy Press; 1993.

8. Oliver A, Mossialos E. Equity of access to health care: outlining the foundations for action. J Epidemiol Community Heal. 2004;58:655-8. https:// doi.org/10.1136/jech.2003.017731.

9. Allin S, Masseria C. Unmet need as an indicator of health care access. Eurohealth (Lond). 2009;15:7-10.

10. Rosano A, Loha CA, Falvo R, Van Der Zee J, Ricciardi W, Guasticchi G, et al. The relationship between avoidable hospitalization and accessibility to primary care: A systematic review. Eur J Public Health. 2013;23:356-60.

11. Gottlieb N, Schülle M. An overview of health policies for asylum-seekers in Germany. Health Policy (New York). 2020. https://doi.org/10.1016/j. healthpol.2020.09.009.

12. Gottlieb N, Hintermeier M, Bozorgmehr K. Situational brief: COVID-19 \& Migration in Germany. London: Lancet Migration Global Collaboration; 2020.

13. Bozorgmehr K, Razum O. Negotiating access to health care for asylum seekers in Germany. In: Health diplomacy: spotlight on refugees and migrants. Copenhagen: WHO Regional Office for Europe; 2019. p. 163-70.

14. Bozorgmehr K, Wenner J, Noest S, Stock C, Razum O. Germany: Financing of health services provided to asylum seekers. In: Compendium of health system responses to large-scale migration in the WHO European Region. Copenhagen: World Health Organization; 2018. p. 38-47.

15. Bozorgmehr K, Razum O. Lost in Ambiguity: Facilitating Access or Upholding Barriers to Health Care for Asylum Seekers in Germany? In: Korntheuer A, Pritchard P, Maehler D, Wilkinson L, Sciences EL-I for S, editors. Refugees in Canada and Germany: From Research to Policies and Practice. GESIS-Schriftenreihe. Vol 25. Köln; 2020. p. 161-70. 
16. Wächter-Raquet M. Einführung der Gesundheitskarte für Asylsuchende und Flüchtlinge. Der Umsetzungsstand im Überblick der Bundesländer. Gütersloh: Bertelsmann Stiftung; 2016.

17. Günther W, Kurrek D, Töller AE. Ein starker Fall für die Parteiendifferenztheorie : Die Einführung der Gesundheitskarte für Asylsuchende in den Bundesländern. Z Polit. 2019;29:361-92.

18. Gottlieb N, Ohm V, Knörnschild M. A first assessment of the electronic health insurance card for asylum seekers in Berlin. Eur J Public Health. 2019:29:302.

19. Rolke K, Wenner J, Razum O. Shaping access to health care for refugees on the local level in Germany - Mixed-methods analysis of official statistics and perspectives of gatekeepers. Health Policy (New York). 2019;123:845-50. https://doi.org/10.1016/j.healthpol.2019.07.001.

20. Spura A, Kleinke M, Robra B-P, Ladebeck N. Wie erleben Asylsuchende den Zugang zu medizinischer Versorgung? Bundesgesundheitsblatt Gesundheitsforsch - Gesundheitsschutz. 2017;60:462-70. https://doi.org/ 10.1007/s00103-017-2525-x

21. Scott P. Black African asylum seekers' experiences of health care access in an eastern German state. Int J Migr Heal Soc Care. 2014;10:134-47. https://doi.org/10.1108/JJMHSC-11-2013-0043.

22. Claassen K, Jäger P. Impact of the Introduction of the Electronic Health Insurance Card on the Use of Medical Services by Asylum Seekers in Germany. Int J Environ Res Public Health. 2018;15:856. https://doi.org/10. 3390/ijerph15050856.

23. Wenner J, Bozorgmehr K, Duwendag S, Rolke K, Razum O. Differences in realized access to healthcare among newly arrived refugees in Germany: results from a natural quasi-experiment. BMC Public Health. 2020;20:846. https://doi.org/10.1186/s12889-020-08981-2.

24. Bozorgmehr K, Razum O. Effect of Restricting Access to Health Care on Health Expenditures among Asylum-Seekers and Refugees: A Quasi-Experimental Study in Germany, 1994-2013. PLoS One. 2015;10:e0131483. https://doi.org/10.1371/journal.pone.0131483.

25. Ohm V, Knörnschild M, Gottlieb N. Die elektronische Gesundheitskarte (eGK) für Asylsuchende in Berlin: eine erste Bilanz. Zeitschrift für Flucht-und Flüchtlingsforschung Sonderband Flucht und. Gesundheit. 2021;219-37. https://doi.org/10.5771/9783748906452-219.

26. Biddle L, Menold N, Bentner M, Nöst S, Jahn R, Ziegler S, et al. Health monitoring among asylum seekers and refugees: A state-wide, crosssectional, population-based study in Germany. Emerg Themes Epidemiol. 2019;16:1-21. https://doi.org/10.1186/s12982-019-0085-2 .

27. Gottlieb N, Püschmann C, Stenzinger F, Koelber J, Rasch L, Koppelow $M$, et al. Health and Healthcare Utilization among Asylum-Seekers from Berlin's LGBTIQ Shelter: Preliminary Results of a Survey. Int J Environ Res Public Health. 2020;17:4514. https://doi.org/10.3390/ijerph17124514.

28. Allin S, Grignon M, Le Grand J. Subjective unmet need and utilization of health care services in Canada: What are the equity implications? Soc Sci Med. 2010;70:465-72. https://doi.org/10.1016/j.socscimed.2009.10.027.

29. Sundmacher L, Fischbach D, Schuettig W, Naumann C, Augustin U, Faisst C. Which hospitalisations are ambulatory care-sensitive, to what degree, and how could the rates be reduced? Results of a group consensus study in Germany. Health Policy (New York). 2015;1 19:1415-23.

30. Public Health Evaluation and Impact Assessment Consortium (PHEIAC). Evaluation of the use and impact of the European Community Health Indicators ECHI by Member States. Final report. European Commission. European Commission Directorate General for Health and Consumers (DG SANCO); 2013.

31. Bozorgmehr K, Schneider C, Joos S. Equity in access to health care among asylum seekers in Germany. BMC Health Serv Res. 2015;15:502.

32. Bauhoff $S$, Gopffarth D. Asylum-seekers in Germany differ from regularly insured in their morbidity, utilizations and costs of care. PLoS One. 2018;13:e0197881.

33. Lichtl C, Lutz T, Szecsenyi J, Bozorgmehr K. Differences in the prevalence of hospitalizations and utilization of emergency outpatient services for ambulatory care sensitive conditions between asylum-seeking children and children of the general population: A cross-sectional medical records study. BMC Health Serv Res. 2017;17:1-9.

34. Davidson PL, Andersen RM, Wyn R, Brown ER. A Framework for Evaluating Safety-Net and other Community-Level Factors on Access for LowIncome Populations. Inq J Heal Care Organ Provision, Financ. 2004;41:2138. https://doi.org/10.5034/inquiryjrnl_41.1.21.
35. Bundesinstitut für Bau-Stadt- und Raumforschung. City and municipal types. 2021. https://www.bbsr.bund.de/BBSR/DE/forschung/raumbeobac htung/Raumabgrenzungen/deutschland/kreise/siedlungsstrukturellekreistypen/kreistypen.html;jsessionid=FF41AFD98EED3E46A0FF66357 693B121. live11314? nn=2544954. Accessed 22 Oct 2021.

36. Ministerium für Inneres Digitalisierung und Migration Baden-Württemberg. Numbers and Statistics. https://im.baden-wuerttemberg.de/ de/migration/auslaender-undfluechtlingspolitik/zahlen-und-daten. Accessed 15 Nov 2018

37. Statistischer WA. Bericht. Leistungen an Asylbewerber im Land Berlin 2018. Berlin: Empfänger von Regelleistungen; 2019.

38. Van Buuren S, Groothuis-Oudshoorn K. Mice : Multivariate Imputation by Chained Equations in R. J Stat Softw. 2011;45. https://doi.org/10.18637/ iss.v045.103.

39. Archer KJ, Lemeshow S. Goodness-of-fit test for a logistic regression model fitted using survey sample data. Stata J. 2006;6:97-105.

40. Scheidt-Nave C, Kamtsiuris P, Gößwald A, Hölling H, Lange M, Busch MA, et al. German health interview and examination survey for adults (DEGS) - design, objectives and implementation of the first data collection wave. BMC Public Health. 2012;12:730. https://doi.org/10.1186/1471-2458-12730.

41. Westle B, Diekmann A, Hadjar A, Kurz K, Rosar U, Wagner U. ALLBUS 2018. 2018. https://www.gesis.org/en/allbus/contents-search/study-profiles1980-to-2018/2018. Accessed 22 Oct 2021.

42. Starfield B. Improving equity in health: A research agenda. Int J Heal Serv. 2001;31:545-66.

43. Gottlieb N, Trummer U, Davidovitch N, Krasnik A, Juárez SP, Rostila M, et al. Economic arguments in migrant health policymaking: proposing a research agenda. Global Health. 2020;16:113. https://doi.org/10.1186/ s12992-020-00642-8.

44. Hollederer A. Guarantee of illness assistance for people seeking asylum: Two-tiered medical system in Germany? Bundesgesundheitsblatt Gesundheitsforsch - Gesundheitsschutz. 2020;63:1203-18.

\section{Publisher's Note}

Springer Nature remains neutral with regard to jurisdictional claims in published maps and institutional affiliations.

Ready to submit your research? Choose BMC and benefit from:

- fast, convenient online submission

- thorough peer review by experienced researchers in your field

- rapid publication on acceptance

- support for research data, including large and complex data types

- gold Open Access which fosters wider collaboration and increased citations

- maximum visibility for your research: over $100 \mathrm{M}$ website views per year

At BMC, research is always in progress.

Learn more biomedcentral.com/submissions 